OPEN ACCESS

Check for updates

\title{
Cardioversion in patients with newly diagnosed non-valvular atrial fibrillation: observational study using prospectively collected registry data
}

\author{
Marita Knudsen Pope, ${ }^{1,2}$ Trygve S Hall, ${ }^{3}$ Valentina Schirripa, ${ }^{4}$ Petra Radic, ${ }^{5}$ Saverio Virdone, ${ }^{6}$ \\ Karen S Pieper, ${ }^{6}$ Jean-Yves Le Heuzey, ${ }^{7}$ Petr Jansky, ${ }^{8}$ David A Fitzmaurice, ${ }^{9}$ Riccardo Cappato, ${ }^{10}$ \\ Dan Atar, ${ }^{1,3}$ A John Camm, ${ }^{11}$ Ajay K Kakkar, ${ }^{6}$ on behalf of the GARFIELD-AF investigators
}

\section{For numbered affiliations see} end of the article

Correspondence to: D Atar dan.atar@medisin.uio.no (or@TRI_Thrombosis on Twitter; ORCID 0000-0003-1513-8793) Additional material is published online only. To view please visit the journal online.

Cite this as: BMJ 2021;375:e066450 http://dx.doi.org/10.1136/ bmj-2021-066450

Accepted: 29 September 2021

\section{ABSTRACT}

OBJECTIVE

To investigate the clinical outcomes of patients who underwent cardioversion compared with those who did not have cardioverson in a large dataset of patients with recent onset non-valvular atrial fibrillation.

\section{DESIGN}

Observational study using prospectively collected registry data (Global Anticoagulant Registry in the FIELD-AF-GARFIELD-AF).

\section{SETTING}

1317 participating sites in 35 countries.

PARTICIPANTS

52057 patients aged 18 years and older with newly diagnosed atrial fibrillation (up to six weeks' duration) and at least one investigator determined stroke risk factor.

\section{MAIN OUTCOME MEASURES}

Comparisons were made between patients who received cardioversion and those who had no cardioversion at baseline, and between patients who received direct current cardioversion and those who had pharmacological cardioversion. Overlap propensity weighting with Cox proportional hazards models was used to evaluate the effect of cardioversion on clinical endpoints (all cause mortality, non-haemorrhagic stroke or systemic embolism, and major bleeding), adjusting for baseline risk and patient selection.

RESULTS

44201 patients were included in the analysis comparing cardioversion and no cardioversion, and

\section{WHAT IS ALREADY KNOWN ON THIS TOPIC}

For decades direct comparisons of rhythm control and rate control strategies in patients with atrial fibrillation have favoured rate control

More recent results from real world observations on the effect of rhythm control versus rate control on clinical endpoints (such as strokes and mortality) in patients with new onset atrial fibrillation are inconclusive

\section{WHAT THIS STUDY ADDS}

A small proportion of patients were treated with cardioversion

Direct current cardioversion was performed twice as often as pharmacological cardioversion, and no major difference in outcome events was found for these two modalities

A lower risk of mortality was observed for patients with newly diagnosed atrial fibrillation who underwent early cardioversion compared with patients who did not have early cardioversion of these, 6595 (14.9\%) underwent cardioversion at baseline. The propensity score weighted hazard ratio for all cause mortality in the cardioversion group was 0.74 (95\% confidence interval 0.63 to 0.86 ) from baseline to one year follow-up and 0.77 (0.64 to 0.93 ) from one year to two year follow-up. Of the 6595 patients who had cardioversion at baseline, 299 had a follow-up cardioversion more than 48 days after enrolment. 7175 patients were assessed in the analysis comparing type of cardioversion: 2427 (33.8\%) received pharmacological cardioversion and 4748 (66.2\%) had direct current cardioversion. During one year follow-up, event rates (per 100 patient years) for all cause mortality in patients who received direct current and pharmacological cardioversion were 1.36 (1.13 to 1.64 ) and 1.70 (1.35 to 2.14 ), respectively.

\section{CONCLUSION}

In this large dataset of patients with recent onset non-valvular atrial fibrillation, a small proportion were treated with cardioversion. Direct current cardioversion was performed twice as often as pharmacological cardioversion, and there appeared to be no major difference in outcome events for these two cardioversion modalities. For the overall cardioversion group, after adjustments for confounders, a significantly lower risk of mortality was found in patients who received early cardioversion compared with those who did not receive early cardioversion.

STUDY REGISTRATION

ClinicalTrials.gov NCT01090362.

\section{Introduction}

After anticoagulation treatment for stroke prevention has been prescribed to appropriate patients (those with increased risk of stroke), there are two main treatment approaches for atrial fibrillation. One approach is to try and restore sinus rhythm, which can be achieved by direct current or pharmacological cardioversion. Rhythm control can potentially relieve symptoms and prevent progression of atrial fibrillation ${ }^{1}$ and left atrial remodelling. ${ }^{2}$ The other treatment option is to allow atrial fibrillation to continue but to control the ventricular rate (rate control). Several randomised controlled trials have shown that this treatment strategy is non-inferior to rhythm control when considering endpoints such as stroke rates and mortality. ${ }^{3-9}$ Previous studies also indicate that rates of hospital admission for rate control are lower than those for rhythm control. ${ }^{4}$ Guidelines in Europe and America support both strategies but stress the need 
for better knowledge about their efficacy and safety. ${ }^{10}$

11 However, the recently reported Early Treatment of Atrial Fibrillation for Stroke Prevention Trial (EAST-AFNET 4) ${ }^{12}$ showed that early rhythm control was superior to guideline mandated management, which consisted largely of rate control until or unless symptoms became refractory.

The Global Anticoagulant Registry in the FIELD-AF (GARFIELD-AF) is a worldwide prospective study of adult patients with newly diagnosed non-valvular atrial fibrillation. ${ }^{1314}$ The registry includes information on baseline patient characteristics, rate of interventions such as cardioversions, and clinical outcomes. Only patients with first time onset of atrial fibrillation within six weeks were included, and so a high proportion might be eligible for an early rhythm control strategy. These data assess the use of cardioversion in daily clinical practice and might provide important information for clinicians treating patients with recent onset non-valvular atrial fibrillation.

In the current study, we aimed to investigate the characteristics of patients who received cardioversion treatment at baseline versus those who did not, and to assess types of cardioversion performed. We also describe the associations between cardioversion and clinical outcomes in a large dataset of patients presenting with recent onset non-valvular atrial fibrillation.

\section{Methods}

Study design

GARFIELD-AF is an international registry of adult patients with newly diagnosed non-valvular atrial fibrillation with at least one additional risk factor for stroke. Patients from 35 countries were prospectively enrolled into five consecutive cohorts of approximately 10000 patients with intended two year follow-up. A total of 52057 patients were enrolled. The registry excluded patients with a transient and reversible cause of atrial fibrillation and those for whom follow-up was not possible. The sites were randomly selected and when this did not generate the required number of sites in a given country, the national lead investigators were asked to recommend sites to make up the numbers (18 of 1317 sites). The sites represent different care settings in each participating country (office based practice; hospital departments including neurology, cardiology, geriatrics, internal medicine, and emergency; anticoagulation clinics; and general or family practice). Outcomes are investigator reported, but a comprehensive audit and quality control system that includes onsite audits and remote quality control measures was enacted in GARFIELD-AF.

\section{Data collection}

Data for the present analysis were extracted from the GARFIELD-AF registry in June 2019. Five independent, prospective cohorts were included from 2010 to 2016. Data were collected from electronic case report forms, which were designed by Dendrite Clinical Systems (Henley-on-Thames, UK). The coordinating centre of the GARFIELD-AF database is the Thrombosis Research Institute (London, UK). Patients were contacted at four monthly intervals by telephone or postal mail. Data were examined for completeness and accuracy by the coordinating centre. In accordance with the study protocol, $20 \%$ of all data submitted electronically were monitored against source documentation. ${ }^{15}$

\section{Content and definitions}

Comparisons were made between patients who received cardioversion and those who had no cardioversion at baseline, and between those who received direct current cardioversion and pharmacological cardioversion throughout the study. Baseline cardioversion was defined as a cardioversion that was reported at baseline or that occurred within 48 days after enrolment to allow for adequate anticoagulation treatment for at least three weeks before cardioversion. Patients who received more than one cardioversion during follow-up were evaluated according to the first type of cardioversion received. Cardioversion type was evaluated by considering cardioversions that occurred at any time during follow-up (type of cardioversion was only reported in the follow-up forms).

At the time of diagnosis, data on clinical characteristics, medical history, cardiovascular risk profile, type of atrial fibrillation, care setting specialty and treatment choice were collected. We applied the GARFIELD-AF risk calculator for measures of stroke, bleeding, and mortality risks; this represents the expected occurrence of each event within two years of enrolment. ${ }^{16}$ The $\mathrm{CHA}_{2} \mathrm{DS}_{2}$-VASc score (congestive heart failure, hypertension, age $>75$, diabetes, stroke or transient ischaemic attack, vascular disease, age $>65$, sex category) was also calculated for risk of stroke. ${ }^{17}$ Atrial fibrillation types were defined according to the European Society of Cardiology guidelines. ${ }^{11}$ Heart failure included patients with current congestive heart failure or a history of the condition, or those with left ventricle ejection fraction $<40 \%$. Vascular disease was defined as peripheral artery disease or coronary artery disease. During follow-up, data on the occurrence of non-haemorrhagic stroke or systemic embolism, major bleeding, and all cause mortality were obtained.

Non-haemorrhagic stroke or systemic embolism was defined as a composite of ischaemic stroke, unknown type stroke, and systemic embolism. Major bleeding was classified by investigators according to the International Society on Thrombosis and Haemostasis definition. Major bleeds, including intracranial bleeds, were defined as a combined endpoint of haemorrhagic stroke and any major bleed. Minor or non-major clinically relevant bleeds that required transfusion, that occurred in a critical site, or were fatal bleeds were reclassified as major bleeds.

\section{Statistical analysis}

Continuous baseline variables are expressed as median (interquartile range) and categorical variables as frequency and percentage. Clinical endpoints of 
the study were all cause mortality, non-haemorrhagic stroke or systemic embolism, and major bleeding. We describe the occurrence of a clinical outcome by using the number of events, event rate per 100 person years, and $95 \%$ confidence interval. Person year rates were estimated using a Poisson model. We only considered the first occurrence of each event.

We calculated the effect of baseline cardioversion on clinical endpoints by using a Cox proportional hazards model with a propensity method of overlap weighting to balance covariates in the population. This newly developed method of overlap propensity weighting avoids excluding patients (as with matching) and gives the most weight to propensities where equipoise exists. This method overlaps weights and optimises the efficiency of comparisons by defining the population with the most overlap in the covariates between treatment groups. This scheme eliminates the potential for outlier weights by avoiding a weight based on a ratio calculation using values bounded by 0 and 1 . Therefore, when using overlap weights, many of the concerns about the assessment and the trimming of the weights are eliminated. ${ }^{18}$ We applied the same method to the comparison of cardioversion techniques.

We used the following variables in the propensity model and supplementary list 1 gives a detailed description of the variables: country and cohort enrolment, sex, age, ethnicity, type of atrial fibrillation, care setting specialty and location, heart failure, acute coronary syndromes, vascular disease, carotid occlusive disease, previous stroke, transient ischaemic attack or systemic embolism, previous bleeding, venous thromboembolism, hypertension, hypercholesterolemia, diabetes, cirrhosis, moderate to severe chronic kidney disease, dementia, hyperthyroidism, hypothyroidism, current smoking, heavy alcohol consumption, body mass index, heart rate, systolic and diastolic blood pressure at diagnosis, baseline anticoagulation, and antiplatelet use. Figures S1 and S2 give absolute standardised differences for all these variables. Figures S3 and S4 show the distribution of the propensity score for the two comparisons.

We estimated the effects of baseline cardioversion for all studied outcomes at one and two years after enrolment. Baseline cardioversions include cardioversions that occurred within 48 days from enrolment. To limit the possible immortal time bias caused by this selection, we also performed landmark analyses for the all cause mortality outcome 48 and 365 days after enrolment. These analyses were not replicated for non-fatal events because of the small number of events.

We carried out two sensitivity analyses. The first analysis included patients with a follow-up cardioversion after enrolment but within 48 days; time at risk was taken from cardioversion instead of enrolment. Secondly, we conducted a time dependent analysis; time at risk started from enrolment and we modified the baseline cardioversion status within 48 days when a cardioversion occurred. Tables S1 and S2 present the results from these analyses. Negligible differences were found compared with the main analyses.

Event occurrence by cardioversion type (pharmacological or direct current) were reported as the number of events and the event rate per 100 person years from time of follow-up cardioversion up to one year. We did not exclude patients with missing values from the study, but single imputation was applied to estimate the baseline cardioversion effect. We performed the imputation procedure assuming arbitrary missing patterns and by applying a fully conditional specification method that assumes a joint distribution for all variables. The fully conditional specification method involves two steps: the filled in phase, where a discriminant function is used for binary variables, logistic for ordinal and regression for continuous variables, filling in sequentially over the variables, one at a time; and the imputation phase. These steps are iterated to obtain final estimates. Table S3 presents the proportion of missing data. Data analysis was performed at the Thrombosis Research Institute with SAS software, version 9.4 (SAS Institute, Cary, NC, USA).

\section{Patient and public involvement}

Members of the study group have performed regular meetings with patient representatives about ongoing scientific projects and activities. There was no explicit funding for patient and public involvement and because this was a multinational study, we did not have enough resources for involvement of patient representatives in all countries that were involved in the study.

\section{Results}

The analyses comparing cardioversion or no cardioversion comprised 44201 patients after we excluded those with unknown cardioversion information $(n=1277)$, those with permanent or unknown type of atrial fibrillation $(n=6546)$, and those with unavailable follow-up information ( $n=33$; fig 1). Of the 6595 patients with a baseline cardioversion, 299 had a follow-up cardioversion that occurred more than 48 days after enrolment. In the analysis comparing type of cardioversion, 7175 patients were assessed: 2427 were treated with pharmacological cardioversion and 4748 with direct current cardioversion.

\section{Baseline patient characteristics: cardioversion versus no cardioversion}

Patients who received cardioversion were younger (median age 67.0 years, interquartile range 58.0-74.0) than those who did not have cardioversion (71.0, 63.078.0, $\mathrm{P}<0.001$; table 1) and a higher proportion had a $\mathrm{CHA}_{2} \mathrm{DS}_{2}$-VASc score of $\leq 1(21.1 \% v 14.4 \%, \mathrm{P}<0.001)$. The proportion of patients with previous stroke, transient ischaemic attack, or systemic embolism in the cardioversion group was around half that reported in the non-cardioversion group $(6.8 \% \vee 11.9 \%$, $\mathrm{P}<0.001$ ), while occurrence of previous bleeding appeared similar between the two groups $(2.3 \% \mathrm{v}$ 


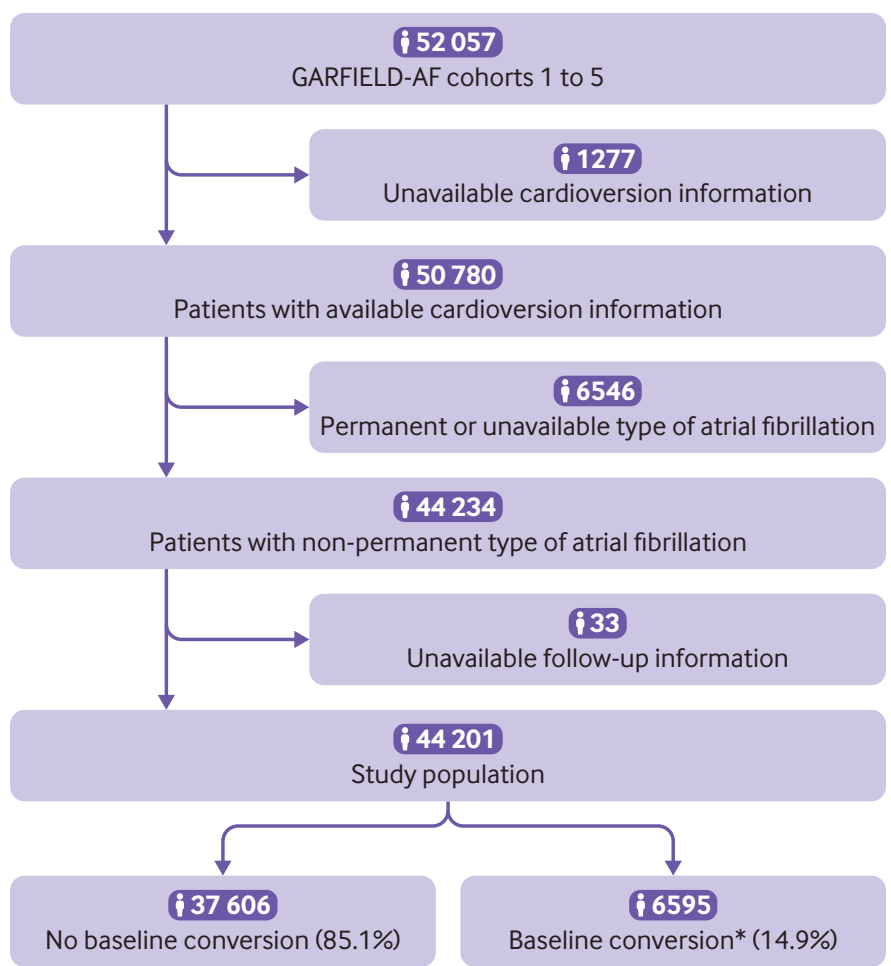

Fig 1 | Flowchart for selection of study population. GARFIELD-AF=Global Anticoagulant Registry in the FIELD-AF. *Baseline cardioversion was defined as cardioversion that was reported at baseline or that occurred within 48 days after enrolment

$2.6 \%, P=0.13)$. The GARFIELD-AF risk scores of death, stroke, and major bleeding were all numerically lower in the cardioversion group.

Table S4 presents the distribution of symptoms at atrial fibrillation diagnosis by cardioversion or no cardioversion at baseline. Patients who underwent cardioversion were more likely to be symptomatic $(85.8 \% \vee 73.9 \%, \mathrm{P}<0.001)$. Table S5 presents the adjunctive treatment results. Antiarrhythmic drugs were taken by $48 \%$ of patients in the cardioversion group and $28 \%$ in the non-cardioversion group $(\mathrm{P}<0.001)$. Ablation was performed in $1.7 \%$ of patients in the cardioversion group and $1.0 \%$ in the noncardioversion group $(\mathrm{P}=0.005)$. Table $\mathrm{S} 6$ gives the baseline cardioversion distribution by country.

Baseline patient characteristics: pharmacological versus direct current cardioversion

The pharmacological cardioversion group had a higher proportion of several comorbidities, including history of heart failure $(26.0 \% v 21.8 \%, \mathrm{P}<0.001)$ and vascular disease $(32.7 \% v 19.9 \%, \mathrm{P}<0.001$; table 1$)$. In contrast, among patients who had pharmacological cardioversion, $6.9 \%$ had a left ventricle ejection fraction $\leq 40 \%$ compared with $15.4 \%$ for those who had direct current cardioversion $(\mathrm{P}<0.001)$. Most patients in both groups had a $\mathrm{CHA}_{2} \mathrm{DS}_{2}$-VASc score $\geq 1 \quad(96.7 \%$ and $95.8 \%$ for pharmacological cardioversion and direct current cardioversion, respectively, $\mathrm{P}=0.08)$. At the beginning of the study, anticoagulation treatment was given less often to patients in the pharmacological cardioversion group than to those in the direct current cardioversion group $(57.6 \% \vee 82.8 \%, \mathrm{P}<0.001)$. The proportion of patients who were treated with pharmacological cardioversion was high in Ukraine, China, and Mexico $(>70 \%)$, while few patients received this treatment in the United States, Singapore, the UK, Sweden, and Norway (<10\%; table 2).

\section{Patient outcomes: cardioversion versus no cardioversion}

The mortality event rates per 100 person years $(95 \%$ confidence interval) from baseline to two year followup were 2.52 (2.26 to 2.81) in the cardioversion group and 3.87 (3.73 to 4.02) in the non-cardioversion group $(\mathrm{P}<0.001)$. After adjusting for differences in baseline risk, the propensity score weighted hazard ratio for all cause mortality in the cardioversion group was 0.74 ( 0.63 to $0.86, \mathrm{P}<0.001)$ from baseline to one year follow-up, 0.77 (0.64 to $0.93, \mathrm{P}=0.008)$ from one year to two year follow-up, and 0.75 (0.67 to 0.85 , $\mathrm{P}<0.001)$ from baseline to two year follow-up. The weighted hazard ratio for cardioversion from baseline to two year follow up was 0.66 (0.54 to $0.82, \mathrm{P}<0.001)$ for cardiovascular mortality and 0.91 (0.75 to 1.09, $\mathrm{P}=0.30$ ) for non-cardiovascular mortality.

In the cardioversion group, the event rate for nonhaemorrhagic stroke or systemic embolism during two year follow-up was 0.79 per 100 person years $(0.65$ to 0.96 ) compared with 1.03 (0.96 to 1.11) for those who did not receive this treatment $(\mathrm{P}=0.01)$. For major bleeds, the event rates were 0.84 (0.69 to 1.01) and 1.02 (0.95 to 1.10$)$, respectively $(\mathrm{P}=0.05)$. No statistically significant beneficial effect of baseline cardioversion was observed for non-fatal outcomes after propensity score weighting. Table 3 and figure 2 depict the event rates and risk estimates for selected time periods for the two groups. Figure 3 provides adjusted cumulative survival probabilities and propensity score weighted hazard ratios for baseline cardioversions versus no cardioversion. From the analysis stratified by the presence of symptoms, no major differences in the effect of cardioversion emerged between patients who were symptomatic and those without symptoms (tables S7 and S8).

The analysis stratified by heart failure showed similar rates for all cause mortality in patients with and without heart failure. For non-haemorrhagic stroke or systemic embolism and major bleeding, the uncertainty around the estimates is too wide to identify any evidence of possible differences (tables S9 and S10).

\section{Patient outcomes: pharmacological versus direct} current cardioversion

Within one year of cardioversion, the mortality event rate per 100 person years was $1.70(95 \%$ confidence interval 1.35 to 2.14 ) for patients treated with pharmacological cardioversion compared with 1.36 (1.13 to 1.64) among those treated with direct current cardioversion $(\mathrm{P}=0.14)$. The rates for nonhaemorrhagic stroke or systemic embolism were 0.50 


\begin{tabular}{|c|c|c|c|c|c|c|}
\hline \multirow[b]{2}{*}{ Baseline characteristics } & \multicolumn{3}{|c|}{ Baseline cardioversion } & \multicolumn{3}{|l|}{ Cardioversion type } \\
\hline & $\begin{array}{l}\text { No } \\
(n=37606)\end{array}$ & $\begin{array}{l}\text { Yes } \\
(n=6595)\end{array}$ & P value* & $\begin{array}{l}\text { Pharmacological } \\
(n=2427)\end{array}$ & $\begin{array}{l}\text { Direct current } \\
(n=4748)\end{array}$ & Pvalue* \\
\hline \multicolumn{7}{|l|}{ Sex } \\
\hline Male & $20689(55.0)$ & $3856(58.5)$ & \multirow[t]{2}{*}{$<0.001$} & $1259(51.9)$ & $3057(64.4)$ & \multirow[t]{2}{*}{$<0.001$} \\
\hline Female & $16917(45.0)$ & $2739(41.5)$ & & $1168(48.1)$ & $1691(35.6)$ & \\
\hline Age (years), median (IQR) & $71.0(63.0-78.0)$ & $67.0(58.0-74.0)$ & $<0.001$ & $66.0(58.0-75.0)$ & $67.0(59.0-74.0)$ & 0.83 \\
\hline \multicolumn{7}{|l|}{ Ethnicity } \\
\hline White & $22012(60.1)$ & $5024(77.9)$ & \multirow[t]{4}{*}{$<0.001$} & $1857(78.6)$ & 3925 (85.9) & \multirow[t]{4}{*}{$<0.001$} \\
\hline Hispanic/Latino & $2450(6.7)$ & $294(4.6)$ & & $158(6.7)$ & $114(2.5)$ & \\
\hline Asian & $11493(31.4)$ & $893(13.9)$ & & $288(12.2)$ & $416(9.1)$ & \\
\hline Afro-Caribbean/mixed/other & $662(1.8)$ & $236(3.7)$ & & $59(2.5)$ & $114(2.5)$ & \\
\hline Body mass index, median (IQR) & $26.7(23.8-30.5)$ & $27.9(24.9-32.0)$ & $<0.001$ & $27.7(24.8-32.0)$ & $28.7(25.6-32.7)$ & $<0.001$ \\
\hline Systolic blood pressure $(\mathrm{mm} \mathrm{Hg})$, median (IQR) & $131.0(120.0-145.0)$ & $130.0(120.0-145.0)$ & 0.04 & $130.0(120.0-146.0)$ & $132.0(120.0-146.0)$ & 0.85 \\
\hline Diastolic blood pressure $(\mathrm{mm} \mathrm{Hg})$, median (IQR) & $80.0(70.0-88.0)$ & $80.0(70.0-90.0)$ & $<0.001$ & $80.0(70.0-90.0)$ & $80.0(74.0-90.0)$ & $<0.001$ \\
\hline Pulse (beats per min), median (IQR) & $83.0(70.0-103.0)$ & $95.0(74.0-122.0)$ & $<0.001$ & $92.0(72.0-126.0)$ & $95.0(77.0-120.0)$ & 0.62 \\
\hline \multicolumn{7}{|l|}{ Type of atrial fibrillation } \\
\hline Persistent & $6291(16.7)$ & $1298(19.7)$ & \multirow[t]{3}{*}{$<0.001$} & $294(12.1)$ & $1222(25.7)$ & \multirow[t]{3}{*}{$<0.001$} \\
\hline Paroxysmal & $12303(32.7)$ & $1680(25.5)$ & & $834(34.4)$ & $676(14.2)$ & \\
\hline New onset (unclassified) & $19012(50.6)$ & $3617(54.8)$ & & $1299(53.5)$ & $2850(60.0)$ & \\
\hline \multicolumn{7}{|l|}{ Care setting specialty at diagnosis } \\
\hline Internal medicine, neurology, geriatrics & $7779(20.7)$ & $1089(16.5)$ & \multirow[t]{3}{*}{$<0.001$} & $452(18.6)$ & $782(16.5)$ & \multirow[t]{3}{*}{$<0.001$} \\
\hline Cardiology & $24831(66.0)$ & $4733(71.8)$ & & $1692(69.7)$ & $3160(66.6)$ & \\
\hline Primary care, general practice & $4996(13.3)$ & $773(11.7)$ & & $283(11.7)$ & $806(17.0)$ & \\
\hline \multicolumn{7}{|l|}{ Care setting location at diagnosis } \\
\hline Hospital & $22194(59.0)$ & $3989(60.5)$ & \multirow[t]{3}{*}{$<0.001$} & $1506(62.1)$ & $2666(56.1)$ & \multirow[t]{3}{*}{$<0.001$} \\
\hline $\begin{array}{l}\text { Office, anticoagulation clinic, thrombosis } \\
\text { centre }\end{array}$ & $11458(30.5)$ & $1276(19.3)$ & & $315(13.0)$ & $1314(27.7)$ & \\
\hline Emergency department & $3954(10.5)$ & $1330(20.2)$ & & $606(25.0)$ & $768(16.2)$ & \\
\hline Medical history & & & & & & \\
\hline Heart failure & $8117(21.6)$ & $1553(23.5)$ & $<0.001$ & $631(26.0)$ & $1036(21.8)$ & $<0.001$ \\
\hline Acute coronary syndromes & $3984(10.6)$ & $786(11.9)$ & 0.001 & $335(13.8)$ & $458(9.7)$ & $<0.001$ \\
\hline Vascular diseaset & $9184(24.6)$ & $1688(25.7)$ & 0.04 & $789(32.7)$ & $942(19.9)$ & $<0.001$ \\
\hline Carotid occlusive disease & $1090(2.9)$ & $180(2.8)$ & 0.45 & $78(3.3)$ & $106(2.3)$ & 0.01 \\
\hline Venous thromboembolism & $964(2.6)$ & $175(2.7)$ & 0.66 & $60(2.5)$ & $139(2.9)$ & 0.27 \\
\hline $\begin{array}{l}\text { Previous stroke, transient ischaemic attack, } \\
\text { systemic embolism }\end{array}$ & $4462(11.9)$ & $444(6.8)$ & $<0.001$ & $190(7.9)$ & $363(7.7)$ & 0.80 \\
\hline Previous bleeding & $967(2.6)$ & $149(2.3)$ & 0.13 & $60(2.5)$ & $105(2.2)$ & 0.48 \\
\hline Hypertension & $28687(76.5)$ & $4947(75.2)$ & 0.03 & $1914(79.0)$ & $3507(74.1)$ & $<0.001$ \\
\hline Hypercholesterolemia & $15102(41.5)$ & $2889(45.1)$ & $<0.001$ & $1138(48.7)$ & $1970(42.8)$ & $<0.001$ \\
\hline Diabetes & $8485(22.6)$ & $1278(19.4)$ & $<0.001$ & $462(19.0)$ & $919(19.4)$ & 0.75 \\
\hline Cirrhosis & $223(0.6)$ & $34(0.5)$ & 0.45 & $14(0.6)$ & $22(0.5)$ & 0.53 \\
\hline Moderate to severe CKD & $3914(10.8)$ & $557(8.7)$ & $<0.001$ & $231(9.8)$ & $393(8.5)$ & 0.07 \\
\hline Dementia & $566(1.5)$ & $46(0.7)$ & $<0.001$ & $19(0.8)$ & $17(0.4)$ & 0.02 \\
\hline Heavy alcohol consumption & $765(2.4)$ & $134(2.4)$ & 0.91 & $35(1.6)$ & $122(3.3)$ & $<0.001$ \\
\hline Current smoker & $3785(11.1)$ & $765(12.7)$ & $<0.001$ & $292(12.8)$ & $541(12.8)$ & 0.10 \\
\hline Treatment & & & & & & \\
\hline New oral anticoagulants \pm antiplatelets & $9825(26.5)$ & $2388(36.9)$ & $<0.001$ & $649(27.5)$ & $1882(40.2)$ & $<0.001$ \\
\hline Vitamin $\mathrm{K}$ antagonists \pm antiplatelets & $14376(38.7)$ & 2189 (33.9) & & $710(30.1)$ & $1992(42.6)$ & \\
\hline Antiplatelets only & $8251(22.2)$ & $1110(17.2)$ & & $671(28.4)$ & $416(8.9)$ & \\
\hline None & $4650(12.5)$ & $779(12.0)$ & & $330(14.0)$ & $390(8.3)$ & \\
\hline $\mathrm{CHA}_{2} \mathrm{DS}_{2}$-VASc score, median (IQR) & $3.0(2.0-4.0)$ & $3.0(2.0-4.0)$ & $<0.001$ & $3.0(2.0-4.0)$ & $3.0(2.0-4.0)$ & $<0.001$ \\
\hline $\mathrm{CHA}_{2} \mathrm{DS}$,-VASc score $\leq 1$ & $5336(14.4)$ & $1373(21.1)$ & $<0.001$ & $418(17.4)$ & $1086(23.1)$ & $<0.001$ \\
\hline HAS-BLED score, median (IQR)‡ & $1.0(1.0-2.0)$ & $1.0(1.0-2.0)$ & $<0.001$ & $1.0(1.0-2.0)$ & $1.0(0.0-2.0)$ & $<0.001$ \\
\hline GARFIELD-AF death score, median (IQR)§ & $4.6(2.5-8.6)$ & $3.9(2.3-7.0)$ & $<0.001$ & $4.1(2.5-7.5)$ & $3.7(2.3-6.4)$ & $<0.001$ \\
\hline GARFIELD-AF stroke score, median (IQR)ף & $1.6(1.1-2.4)$ & $1.3(0.9-1.9)$ & $<0.001$ & $1.4(1.0-2.1)$ & $1.2(0.9-1.8)$ & $<0.001$ \\
\hline GARFIELD-AF bleeding score, median (IQR) ${ }^{\star \star}$ & $1.6(1.0-2.4)$ & $1.3(0.9-2.1)$ & $<0.001$ & $1.3(0.8-2.1)$ & $1.3(0.8-2.1)$ & 0.02 \\
\hline 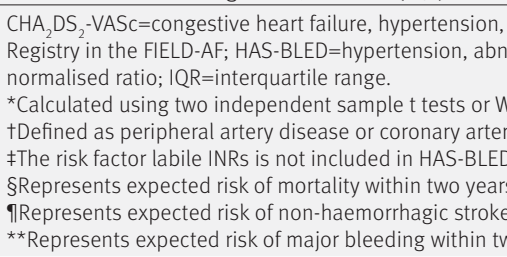 & $\begin{array}{l}\text { ge } 75 \text {, diabetes, stroke or } \\
\text { mal renal or liver function, } \\
\text { coxon-Mann-Whitney tests } \\
\text { disease. } \\
\text { core because it is not colle } \\
\text { r systemic embolism within }\end{array}$ & $\begin{array}{l}\text { ansient ischaemic attack, } v \\
\text { roke, bleeding tendency o } \\
\text { r continuous variables, as } \\
\text { ed at baseline. As a result, } \\
\text { wo years. }\end{array}$ & $\begin{array}{l}\text { scular diseas } \\
\text { predispositio } \\
\text { ppropriate, a } \\
\text { naximum HA }\end{array}$ & $\begin{array}{l}\text { age }>65 \text {, sex category; } \\
\text { labile INR, elderly ( }>65 \text { ye } \\
\mathrm{dx}^{2} \text { or Fisher exact test fo } \\
\text { BLED score at baseline is }\end{array}$ & $\begin{array}{l}\text { FIELD-AF=Global Anticoag } \\
\text { s), drugs or alcohol; INR= } \\
\text { ategorical variables, as ap } \\
\text { (not 9). }\end{array}$ & $\begin{array}{l}\text { ant } \\
\text { ternational } \\
\text { ropriate. }\end{array}$ \\
\hline
\end{tabular}

(0.33 to 0.76 ) and 0.47 (0.34 to 0.65$)$, respectively $(\mathrm{P}=0.84)$, and for major bleeds 0.55 (0.36 to 0.82$)$ and 0.64 (0.48 to 0.84$)$, respectively $(\mathrm{P}=0.55$; table
4). After adjusting for differences in baseline risk, the propensity score weighted hazard ratio for all cause mortality in the pharmacological cardioversion group 


\begin{tabular}{lll}
\hline \multicolumn{3}{l}{ Table 2 | Distribution of cardioversion type by country } \\
Country & Pharmacological (row \%) & Direct current (row \%) \\
Ukraine $(n=519)$ & 78.8 & 21.2 \\
\hline China $(n=97)$ & 77.3 & 22.7 \\
\hline Mexico $(n=48)$ & 72.9 & 27.1 \\
\hline Russia $(n=370)$ & 69.5 & 30.5 \\
\hline United Arab Emirates $(n=87)$ & 63.2 & 36.8 \\
\hline Chile $(n=83)$ & 62.6 & 37.4 \\
\hline India $(n=32)$ & 62.5 & 37.5 \\
\hline Egypt $(n=85)$ & 60.0 & 40.0 \\
\hline Japan $(n=149)$ & 58.4 & 41.6 \\
\hline Argentina $(n=136)$ & 53.7 & 46.3 \\
\hline Hungary $(n=243)$ & 51.8 & 48.2 \\
\hline taly $(n=253)$ & 45.4 & 54.6 \\
\hline Brazil $(n=154)$ & 44.2 & 55.8 \\
\hline Spain $(n=312)$ & 41.7 & 58.3 \\
\hline Canada $(n=133)$ & 39.9 & 60.1 \\
\hline France $(n=287)$ & 33.5 & 66.5 \\
\hline Thailand $(n=25)$ & 32.0 & 68.0 \\
\hline Switzerland $(n=22)$ & 31.8 & 68.2 \\
\hline Poland $(n=584)$ & 30.1 & 69.9 \\
\hline Turkey $(n=107)$ & 26.2 & 73.8 \\
\hline Czech Republic $(n=374)$ & 25.9 & 74.1 \\
\hline Austria $(n=45)$ & 24.4 & 75.6 \\
\hline Denmark $(n=137)$ & 24.1 & 75.9 \\
\hline Australia $(n=214)$ & 19.2 & 80.8 \\
\hline Belgium $(n=670)$ & 16.1 & 83.9 \\
\hline Germany $(n=374)$ & 15.8 & 84.2 \\
\hline South Korea $(n=265)$ & 15.1 & 84.9 \\
\hline South Africa $(n=169)$ & 13.6 & 86.4 \\
\hline Finland $(n=121)$ & 13.2 & 86.8 \\
\hline Netherlands $(n=315)$ & 10.2 & 89.8 \\
\hline United States $(n=193)$ & 9.8 & 90.2 \\
\hline Singapore $(n=13)$ & 7.7 & 92.3 \\
\hline United Kingdom $(n=260)$ & 7.3 & 92.7 \\
\hline Sweden $(n=234)$ & 2.6 & 97.4 \\
\hline Norway $(n=65)$ & 1.5 & 98.5 \\
\hline & & \\
\hline
\end{tabular}

compared with the direct current cardioversion group was 1.27 (0.89 to $1.80, \mathrm{P}=0.18$ ).

\section{Discussion}

In this study of a large sample of patients with recent onset atrial fibrillation who were followed up for two years, a small number received cardioversion at baseline. Importantly, we found that patients treated with baseline cardioversion appeared to have a significantly lower mortality risk during follow-up after adjustment for known confounders (event rates per 100 patient years $2.52 \vee 3.87$, weighted hazard ratio $0.75,95 \%$ confidence interval 0.67 to $0.85, \mathrm{P}<0.001$ ). Our analyses show that most patients treated with cardioversion receive a direct current approach. Event rates for all cause mortality in these patients, given differences in baseline risk, appear similar to those for patients who received pharmacological cardioversion.

Of the 44201 patients included in the analysis of cardioversion versus no cardioversion at baseline, an attempt was made to restore sinus rhythm in only 14.9\%. Given that the study population consisted of patients with newly diagnosed atrial fibrillation, this number seems low. Studies suggest that recent onset atrial fibrillation responds favourably to rhythm control $^{10} 111920$ because a long duration of atrial fibrillation could make cardioversion less likely to succeed. ${ }^{21-24}$ Additionally, patients may experience symptom relief after rhythm control even when not obviously symptomatic before cardioversion. ${ }^{25} \quad 26$ Therefore, international guidelines suggest a rhythm control strategy should be considered with the aim of reducing atrial fibrillation related symptoms and improving quality of life. ${ }^{11}$ However, several randomised controlled trials comparing rate control and rhythm control strategies have not found significant differences in mortality rates or other adverse outcomes, but a higher hospital rate has been reported for rhythm control..$^{3-9}$ In the recently published EAST-AFNET $4^{12}$ that included patients diagnosed one year or less before enrolment, a rhythm control strategy was associated with a lower risk of cardiovascular outcomes and a similar hospital admission rate compared with usual care among patients with early atrial fibrillation and cardiovascular conditions. Our observations support a rhythm control strategy being

\begin{tabular}{|c|c|c|c|c|c|c|}
\hline \multirow{2}{*}{$\begin{array}{l}\text { Outcome, time } \\
\text { period (days) }\end{array}$} & \multicolumn{2}{|c|}{ No baseline cardioversion } & \multicolumn{2}{|c|}{ Baseline cardioversion } & \multirow[b]{2}{*}{ Crude HR $(95 \% \mathrm{CI}) \dagger$} & \multirow{2}{*}{$\begin{array}{l}\text { Propensity score } \\
\text { weighted HR }(95 \% \mathrm{Cl}) \dagger\end{array}$} \\
\hline & Events & Rate $(95 \% \mathrm{Cl})$ & Events & Rate $(95 \% \mathrm{Cl})$ & & \\
\hline \multicolumn{7}{|c|}{ All cause mortality } \\
\hline $0-48$ & 291 & $5.92(5.28$ to 6.65$)$ & 40 & 4.64 (3.40 to 6.32$)$ & 0.78 (0.56 to 1.09$)$ & $0.83(0.59$ to 1.17$)$ \\
\hline $49-365$ & 1284 & $4.10(3.88$ to 4.33$)$ & 145 & $2.60(2.21$ to 3.06$)$ & $0.64(0.54$ to 0.75$)$ & $0.71(0.60$ to 0.85$)$ \\
\hline $366-730$ & 1130 & 3.35 (3.16 to 3.56$)$ & 131 & 2.14 (1.81 to 2.55$)$ & 0.64 (0.53 to 0.77$)$ & 0.77 (0.64 to 0.93$)$ \\
\hline $0-365$ & 1575 & $4.35(4.14$ to 4.57$)$ & 185 & 2.87 (2.49 to 3.32$)$ & $0.66(0.57$ to 0.77$)$ & $0.74(0.63$ to 0.86$)$ \\
\hline $0-730$ & 2705 & 3.87 (3.73 to 4.02$)$ & 316 & $2.52(2.26$ to 2.81$)$ & $0.65(0.58$ to 0.73$)$ & $0.75(0.67$ to 0.85$)$ \\
\hline \multicolumn{7}{|c|}{ Non-haemorrhagic stroke or systemic embolism } \\
\hline $0-365$ & 443 & $1.23(1.12$ to 1.35$)$ & 61 & $0.95(0.74$ to 1.22$)$ & $0.78(0.59$ to 1.01$)$ & $0.92(0.69$ to 1.23$)$ \\
\hline $0-730$ & 716 & $1.03(0.96$ to 1.11$)$ & 98 & $0.79(0.65$ to 0.96$)$ & $0.76(0.62$ to 0.94$)$ & $0.93(0.75$ to 1.17$)$ \\
\hline \multicolumn{7}{|l|}{ Major bleeding } \\
\hline $0-365$ & 476 & $1.32(1.21$ to 1.45$)$ & 65 & $1.01(0.80$ to 1.29$)$ & $0.77(0.59$ to 1.00$)$ & $0.78(0.59$ to 1.02$)$ \\
\hline $0-730$ & 709 & $1.02(0.95$ to 1.10$)$ & 104 & $0.84(0.69$ to 1.01$)$ & $0.82(0.67$ to 1.01$)$ & $0.85(0.69$ to 1.06$)$ \\
\hline \multicolumn{7}{|c|}{$\begin{array}{l}\text { HR=hazard ratio. } \\
\text { *Obtained using an overlap weighted Cox model. Variables included in weighting scheme are as follows: country and cohort enrolment, sex, age, } \\
\text { ethnicity, type of atrial fibrillation, care setting specialty and location, congestive heart failure, acute coronary syndromes, vascular disease, carotid } \\
\text { occlusive disease, previous stroke, transient ischaemic attack or systemic embolism, previous bleeding, venous thromboembolism, hypertension, } \\
\text { hypercholesterolemia, diabetes, cirrhosis, moderate to severe chronic kidney disease, dementia, hyperthyroidism, hypothyroidism, current smoking, } \\
\text { heavy alcohol consumption, body mass index, heart rate, systolic and diastolic blood pressure at diagnosis, baseline anticoagulation, and antiplatelet } \\
\text { use. } \\
\text { tReference: no baseline cardioversion. }\end{array}$} \\
\hline
\end{tabular}




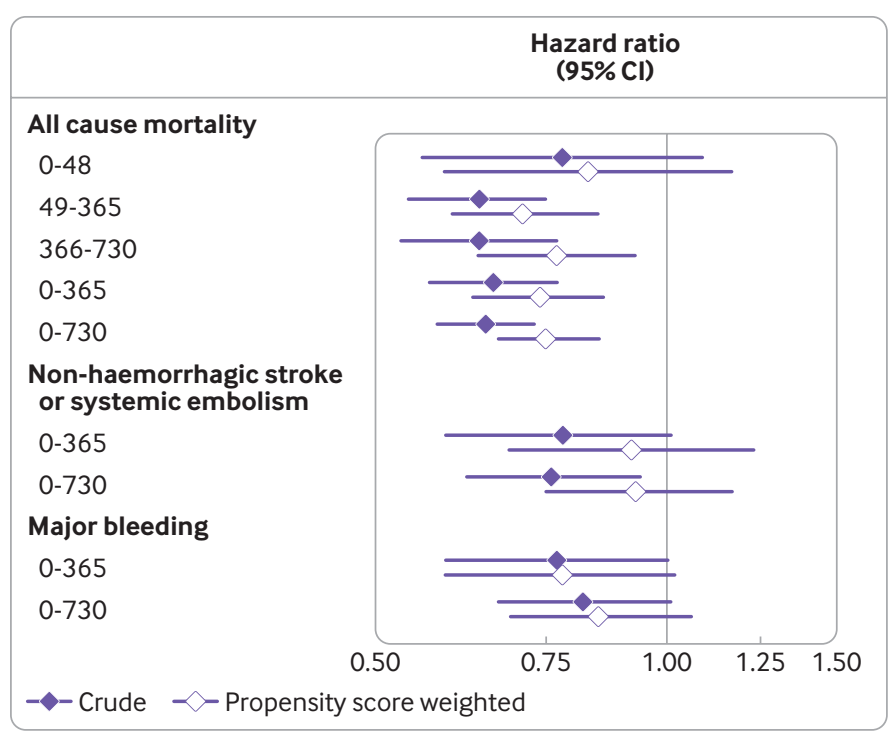

Fig 2 | Crude and propensity score weighted hazard ratios by baseline cardioversion (reference: no baseline conversion) for selected time periods. Hazard ratios obtained by using an overlap weighted Cox model. Variables included in the weighting scheme are country and cohort enrolment, sex, age, ethnicity, type of atrial fibrillation, care setting speciality and location, congestive heart failure, acute coronary syndromes, vascular disease, carotid occlusive disease, previous stroke, transient ischaemic attack or systemic embolism, previous bleeding, venous thromboembolism, hypertension, hypercholesterolemia, diabetes, cirrhosis, moderate to severe chronic kidney disease, dementia, hyperthyroidism, hypothyroidism, current smoking, heavy alcohol consumption, body mass index, heart rate, systolic and diastolic blood pressure at diagnosis, baseline anticoagulation, and antiplatelet use

beneficial for patients with recent onset non-valvular atrial fibrillation.

In our dataset, direct current cardioversion was performed twice as often as pharmacological cardioversion. Previous data support the concept that direct current cardioversion has a higher success rate than pharmacological cardioversion, ${ }^{22}{ }^{27}$ with quicker onset of effect, less monitoring, and fewer hospital admissions. ${ }^{282}$ Therefore, direct current cardioversion has emerged as the method of choice, although from a patient perspective, pharmacological cardioversion is often perceived as less frightening. Because of an increased risk of severe side effects, the options available for pharmacological cardioversion in patients with heart failure and reduced ejection fraction are

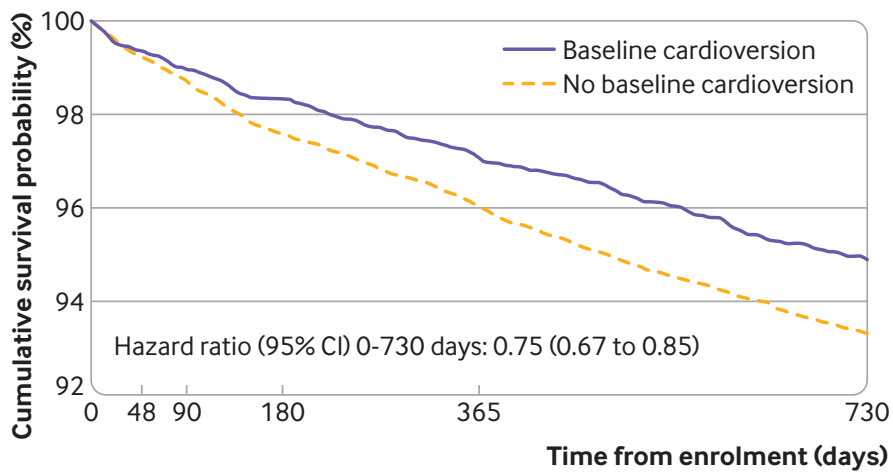

Fig 3 | Adjusted cumulative survival probabilities by baseline cardioversion and propensity score weighted hazard ratio for baseline cardioversion versus no baseline cardioversion (reference) limited. Amiodarone is often preferred but has a later onset of effect than other antiarrhythmic drugs. ${ }^{11263031}$ Therefore, when patients are considered for a rhythm control strategy, direct current cardioversion might be more appropriate. In our dataset, a higher proportion of patients in the direct current cardioversion group were observed to have a left ventricle ejection fraction $<40 \%$. Additionally, we believe that a driver for the difference between these groups might be that this form of cardioversion is preferred by clinicians, in accordance with current guidelines, for patients who are haemodynamically unstable. ${ }^{1011}$ Nevertheless, the pharmacological cardioversion group had a higher proportion of patients with coronary artery disease.

Patients in GARFIELD-AF had at least one nonspecified risk factor for stroke, and in our analysis of cardioversion type, we found that more than $95 \%$ in both cardioversion groups had a $\mathrm{CHA}_{2} \mathrm{DS}_{2}$ VASc score $\geq 1$. However, only $57.6 \%$ of patients who received pharmacological cardioversion were treated with anticoagulants at baseline. The number was higher in the direct current cardioversion group in which $82.8 \%$ received anticoagulants. Most of our sample had an increased risk of stroke, and so it might have been more beneficial for patient outcome if a higher anticoagulation rate had been achieved. Anticoagulation treatment was registered at baseline. For some patients the choice of cardioversion could have come later and anticoagulation treatment might have been started at that point.

Considerable variations were found in choice of cardioversion modality from country to country. Patient comorbidities, treatment choice, and follow-up opportunities in the different countries might therefore have contributed to the differences observed between the two groups in the cardioversion modality analysis.

In the analysis comparing cardioversion with no cardioversion we found that fewer patients in the cardioversion group experienced a severe clinical event (all cause mortality, non-haemorrhagic stroke or systemic embolism, or major bleed) in the first year and from baseline to two year follow-up. Patients who received cardioversion had a lower risk profile at baseline. To better evaluate the effect of cardioversion, weighted hazard ratio prediction models were used. After adjusting for baseline risk, we found that there was a significant difference in mortality among the two treatment groups, within one and two years of follow-up. The lower all cause mortality rate was driven by less cardiovascular mortality. Risks of nonhaemorrhagic stroke or systemic embolism, and major bleeding trended in the same direction. In two sensitivity analyses (the first with time at risk changed from time of inclusion to time of cardioversion; the second, with time at risk from time of inclusion but with baseline cardioversion status modified if cardioversion occurred), only negligible differences were found compared with the main analysis. Our study reported significantly lower rates of mortality in the cardioversion group and supports the use of rhythm control strategies over rate control strategies. 


\begin{tabular}{|c|c|c|c|c|c|c|}
\hline \multirow[b]{2}{*}{ Outcome } & \multicolumn{2}{|c|}{ Pharmacological } & \multicolumn{2}{|c|}{ Direct current } & \multirow[b]{2}{*}{ Crude HR $(95 \% \mathrm{CI}) *$} & \multirow{2}{*}{$\begin{array}{l}\text { Propensity score } \\
\text { weighted HR }(95 \% \mathrm{CI})^{\star}\end{array}$} \\
\hline & Events & Rate $(95 \% \mathrm{Cl})$ & Events & Rate $(95 \% \mathrm{Cl})$ & & \\
\hline $\begin{array}{l}\text { Non-haemorrhagic stroke } \\
\text { or systemic embolism }\end{array}$ & 21 & $0.50(0.33$ to 0.76$)$ & 38 & $0.47(0.34$ to 0.65$)$ & $1.09(0.64$ to 1.85$)$ & 0.89 (0.47 to 1.68$)$ \\
\hline Major bleeding & 23 & $0.55(0.36$ to 0.82$)$ & 51 & 0.64 (0.48 to 0.84$)$ & $0.89(0.54$ to 1.45$)$ & 1.03 (0.59 to 1.83$)$ \\
\hline
\end{tabular}

Rhythm control strategies were started early after atrial fibrillation diagnosis in our study and in EAST-AFNET 4 , which is in contrast to previous studies ${ }^{6-8}$; this might have contributed to the better outcomes reported in the rhythm control groups.

There was a trend of lower event rates in our study compared with the recently published EAST-AFNET 4. When considering baseline characteristics, we found that patients in GARFIELD-AF (in baseline cardioversion and no baseline cardioversion groups) appeared to have lower risk profiles than both study groups in EAST-AFNET 4. Additionally, EAST-AFNET 4 had a median follow-up of 5.1 years, while in GARFIELD-AF the follow-up was two years. This longer observational period subsequently leads to a study sample with more aged patients with higher risk (both studies only included patients with newly diagnosed atrial fibrillation). Therefore, a better risk profile at baseline combined with a shorter observational period are some potential causes of the lower event rates presented in our study. In contrast to EAST-AFNET, the Catheter Ablation versus Antiarrhythmic Drug Therapy for Atrial Fibrillation (CABANA) study ${ }^{32}$ reported similar mortality rates. Follow-up in the CABANA study was longer than in the present study, but baseline characteristics appeared comparable.

When we analysed patients who received pharmacological or direct current cardioversion, we found that the event rates for non-haemorrhagic stroke or systemic embolism, and major bleeding within the first year of cardioversion were similar in the two groups. After adjusting for known confounders, we found no significant difference in mortality rates. The low number of events made it difficult to obtain robust hazard ratio estimates to compare cardioversion type effects on other outcomes.

\section{Strengths and limitations of the study}

One strength of the GARFIELD-AF registry is the large study sample with patients represented from many countries, which improves generalisability to real world clinical practice. Data in the registry are observational and non-randomised, and for any comparisons the data had to be adjusted for potential confounding baseline factors. Cardioversion was not randomised and the rationale for varying treatment decisions is unknown; although robust statistical methods were used to account for differences between groups, the potential for residual confounding cannot be ruled out. Although several possible confounders were included in the propensity score weighting scheme, we were not able to account for factors such as healthier lifestyle, better surveillance, and adjunctive treatment. Other unrecognised factors might also have influenced the results and the application of falsification endpoints to check for residual confounding was not deemed feasible with the available recorded outcomes.

Information on type of cardioversion was only available from the follow-up forms and the modality is therefore not known for all cardioversions performed. Data on success and duration of a successfully restored sinus rhythm were not obtained. The precise treatment given for pharmacological cardioversion was not collected.

The decision to separate baseline cardioversions from follow-up cardioversions at 48 days was based on the requirement of previous anticoagulation treatment, and therefore this was an arbitrary choice. The analysis and the comparison between cardioversion and no cardioversion were applied to this group. Therefore, the results presented in this study might not be generalisable to patients with longer duration of atrial fibrillation. In the cardioversion type analysis, event rates were too low to calculate adjusted hazard ratios for non-fatal events. Therefore, differences in the baseline risk profile between the two groups should be taken into account when interpreting the results.

Clinical event rates were evaluated after two years in the cardioversion versus no cardioversion analysis and after one year when analysing the type of cardioversion. A longer observation time would be valuable when assessing the long-terms effects of the different interventions.

\section{Conclusions}

In this large dataset of patients with recent onset nonvalvular atrial fibrillation, a small proportion were treated with cardioversion. Direct current cardioversion was performed twice as often as pharmacological cardioversion. No major difference in outcome events was observed for these two cardioversion modalities. For the overall cardioversion group, after adjusting for confounders, a significantly lower risk of mortality was found in patients who received cardioversion at baseline compared with those who did not receive this treatment at baseline.

\section{AUTHOR AFFILIATIONS}

${ }^{1}$ Institute of Clinical Medicine, University of Oslo, Oslo, Norway

${ }^{2}$ Hamar Hospital, Innlandet Hospital Trust, Hamar, Norway

${ }^{3}$ Department of Cardiology, Oslo University Hospital, Ullevål, Oslo, Norway

${ }^{4}$ Cardiology Department, G B Grassi Hospital, Rome, Italy 
${ }^{5}$ School of Medicine, University of Zagreb, Zagreb, Croatia

${ }^{6}$ Thrombosis Research Institute, London, UK

${ }^{7}$ Department of Cardiology, Georges Pompidou Hospital, René Descartes University, Paris, France

${ }^{8}$ Department of Cardiovascular Surgery, Motol University Hospital, Prague, Czech Republic

${ }^{9}$ Warwick Medical School, University of Warwick Medical School, Coventry, UK

${ }^{10}$ Arrhythmia \& Electrophysiology Centre, IRCCS MultiMedica Group, Sesto San Giovanni, Milan, Italy

${ }^{11}$ Cardiology Clinical Academic Group Molecular \& Clinical Sciences Research Institute, St George's University of London, London, UK

We thank physicians, nurses, and patients contributing to the GARFIELD-AF registry. Editorial support was provided by Dr Surekha Damineni (Thrombosis Research Institute, London, UK). Programming support was provided by Madhusudana Rao (Thrombosis Research Institute). A complete list of investigators is given in the supplementary file.

Contributors: IYLH, PI, DAF, DA, AIC, and AKK contributed to the study design. SV and KSP analysed the data. MKP, TSH, and RC provided the interpretation of results and contributed to the drafting. All authors supervised the data analysis, provided the interpretation of results, and contributed to the drafting and critical review of the manuscript. All authors approved the final draft. The corresponding author attests that all listed authors meet authorship criteria and that no others meeting the criteria have been omitted. DA is the guarantor of this study.

Funding: This work is supported by Kantor Charitable Foundation for the Kantor-Kakkar Global Centre for Thrombosis Science. The funding source had no involvement in trial design, collection and analysis of data, or in the writing process of this paper.

Competing interests: All authors have completed the ICMJE uniform disclosure form at www.icmie.org/disclosure-of-interest/ and declare: support from Kantor Charitable Foundation for the Kantor-Kakkar Global Centre for Thrombosis Science for the submitted work. TSH reports personal fees from AstraZeneca, Bayer, Boehringer Ingelheim, Bristol-Myers Squibb, Imedic, Novartis, MSD, Sanofi, and Pfizer. JYLH reports personal fees from Bayer, BMS/Pfizer, Boehringer Ingelheim, and Daiichi-Sankyo. PJ has served as a consultant or on an advisory board for Bayer, Boehringer Ingelheim, and Novartis. RC reports research grants from Boston Scientific, Medtronic, Abbott, Pfizer, Daiichi Sankyo, Biosense Webster, Boehringer Ingelheim, Johnson and Johnson, and personal fees from Boston Scientific, Medtronic, Biosense Webster, Abbott. DA reports personal fees from Bayer, Boehringer-Ingelheim, Bristol Meier Squibb, MSD and Pfizer, and grants to the institution from Medtronic and BMS. AIC has received institutional grant funding and personal fees from Bayer, Boehringer Ingelheim, Bristol Meier Squibb, Daiichi Sankyo, and Pfizer. AKK has received grants from Bayer $A G$, and Sanofi, personal fees from Bayer AG, Janssen, Pfizer, Sanofi, Verseon, and Anthos Therapeutics. All other authors have reported that they have no relationships relevant to the content of this paper to disclose.

Patient consent: Obtained.

Ethical approval: All patients signed written informed consent to participate before enrolment. Approvals for the registry protocol were obtained from independent ethics committees or hospital based institutional boards. The database is being conducted according to the principles of the Declaration of Helsinki and the International Conference on Harmonisation-Good Pharmaco-epidemiological and Clinical Practice guidelines.

Data sharing: Requests for patient level data can be made to the head of statistics at the Thrombosis Research Institute (kpieper@ tri-london.ac.uk). These requests should include a protocol summary and a summary of the statistical analysis plan. The request will be reviewed by the data sharing committee for approval and next steps will be discussed with the requestor.

The lead author (DA) affirms that this manuscript is an honest, accurate, and transparent account of the study being reported; that no important aspects of the study have been omitted; and that any discrepancies from the study as planned have been explained.

Dissemination to participants and related patient and public communities: We plan to disseminate the results to clinical study sites. We also plan to disseminate the research results through media releases (mainly by the research institutions of the authors), and to distribute the paper to clinicians.
Provenance and peer review: Not commissioned; externally peer reviewed.

This is an Open Access article distributed in accordance with the Creative Commons Attribution Non Commercial (CC BY-NC 4.0) license, which permits others to distribute, remix, adapt, build upon this work non-commercially, and license their derivative works on different terms, provided the original work is properly cited and the use is noncommercial. See: http://creativecommons.org/licenses/by-nc/4.0/.

1 Zhang YY, Qiu C, Davis PJ, et al. Predictors of progression of recently diagnosed atrial fibrillation in REgistry on Cardiac Rhythm DisORDers Assessing the Control of Atrial Fibrillation (RecordAF)United States cohort. Am J Cardiol 2013;112:79-84. doi:10.1016/j. amjcard.2013.02.056

2 Nattel S, Burstein B, Dobrev D. Atrial remodeling and atrial fibrillation: mechanisms and implications. Circ Arrhythm Electrophysiol 2008;1:62-73. doi:10.1161/CIRCEP.107.754564

3 Al-Khatib SM, Allen LaPointe NM, Chatterjee R, et al. Rate- and rhythm-control therapies in patients with atrial fibrillation: a systematic review. Ann Intern Med 2014:160:760-73. doi:10.7326/ M13-1467

4 Chatteriee S, Sardar P, Lichstein E, Mukherjee D, Aikat S. Pharmacologic rate versus rhythm-control strategies in atria fibrillation: an updated comprehensive review and meta-analysis. Pacing Clin Electrophysiol 2013;36:122-33. doi:10.1111/j.1540$8159.2012 .03513 x$

5 de Denus S, Sanoski CA, Carlsson J, Opolski G, Spinler SA. Rate vs rhythm control in patients with atrial fibrillation: a meta-analysis. Arch Intern Med 2005:165:258-62. doi:10.1001/archinte.165.3.258

6 Roy D, Talajic M, Nattel S, et al, Atrial Fibrillation and Congestive Heart Failure Investigators. Rhythm control versus rate control for atrial fibrillation and heart failure. N Engl / Med 2008:358:2667-77. doi.10.1056/NEIMoa0708789

7 Wyse DG, Waldo AL, DiMarco JP, et al, Atrial Fibrillation Follow-up Investigation of Rhythm Management (AFFIRM) Investigators. A comparison of rate control and rhythm control in patients with atrial fibrillation. N Engl / Med 2002;347:1825-33. doi:10.1056/ NEJMoa021328

8 Van Gelder IC, Hagens VE, Bosker HA, et al, Rate Control versus Electrical Cardioversion for Persistent Atrial Fibrillation Study Group. A comparison of rate control and rhythm control in patients with recurrent persistent atrial fibrillation. N Engl J Med 2002;347:183440. doi:10.1056/NEIMoa021375

9 Kotecha D, Kirchhof P. Rate and rhythm control have comparable effects on mortality and stroke in atrial fibrillation but better data are needed. Evid Based Med 2014:19:222-3. doi:10.1136/ ebmed-2014-110062

10 January CT, Wann LS, Alpert JS, et al, American College of Cardiology/ American Heart Association Task Force on Practice Guidelines. 2014 AHA/ACC/HRS guideline for the management of patients with atrial fibrillation: a report of the American College of Cardiology/American Heart Association Task Force on Practice Guidelines and the Heart Rhythm Society. J Am Coll Cardiol 2014:64:e1-76. doi:10.1016/i. jacc.2014.03.022

11 Hindricks G, Potpara T, Dagres N, et al, ESC Scientific Document Group. 2020 ESC Guidelines for the diagnosis and management of atrial fibrillation developed in collaboration with the European Association for Cardio-Thoracic Surgery (EACTS): The Task Force for the diagnosis and management of atrial fibrillation of the European Society of Cardiology (ESC) Developed with the special contribution of the European Heart Rhythm Association (EHRA) of the ESC. Eur Heart/ 2021;42:373-498. doi:10.1093/eurheartj/ehaa612

12 Kirchhof P, Camm AJ, Goette A, et al, EAST-AFNET 4 Trial Investigators. Early Rhythm-Control Therapy in Patients with Atrial Fibrillation. N Engl J Med 2020;383:1305-16. doi:10.1056/NEJMoa2019422

13 Kakkar AK, Mueller I, Bassand IP et al International longitudinal registry of patients with atrial fibrillation at risk of stroke: Global Anticoagulant Registry in the FIELD (GARFIELD). Am Heart 12012:163:13-19.e1. doi:10.1016/j.ahi.2011.09.011

14 Kakkar AK, Mueller I, Bassand IP, et al, GARFIELD Registry Investigators. Risk profiles and antithrombotic treatment of patients newly diagnosed with atrial fibrillation at risk of stroke: perspectives from the international, observational, prospective GARFIELD registry. PLoS One 2013;8:e63479. doi:10.1371/journal.pone.0063479

15 Fox KAA, Gersh BJ, Traore S, et al, GARFIELD-AF Investigators. Evolving quality standards for large-scale registries: the GARFIELD-AF experience. Eur Heart / Qual Care Clin Outcomes 2017;3:114-22. doi:10.1093/ehjqcco/qcw058

16 Fox KAA, Lucas JE, Pieper KS, et al, GARFIELD-AF Investigators. Improved risk stratification of patients with atrial fibrillation: an integrated GARFIELD-AF tool for the prediction of mortality, stroke and bleed in patients with and without anticoagulation. BMJ Open 2017:7:e017157. doi:10.1136/bmjopen-2017-017157 
17 Lip GY, Nieuwlaat R, Pisters R, Lane DA, Crijns HJ. Refining clinical risk stratification for predicting stroke and thromboembolism in atrial fibrillation using a novel risk factor-based approach: the euro heart survey on atrial fibrillation. Chest 2010;137:263-72. doi:10.1378/ chest.09-1584

18 Li F, Thomas LE, Li F. Addressing Extreme Propensity Scores via the Overlap Weights. Am J Epidemiol 2019;188:250-7. doi:10.1093/ aje/kwy201

19 Kirchhof P, BaxJ, Blomstrom-Lundquist C, et al. Early and comprehensive management of atrial fibrillation: executive summary of the proceedings from the 2nd AFNET-EHRA consensus conference 'research perspectives in AF'. Eur Heart / 2009;30:2969-77c. doi:10.1093/eurheartj/ehp235

20 Van Gelder IC, Haegeli LM, Brandes A, et al. Rationale and current perspective for early rhythm control therapy in atrial fibrillation. Europace 2011:13:1517-25 doi:10.1093/europace/eur192

21 Cosio FG, Aliot E, Botto GL, et al. Delayed rhythm control of atrial fibrillation may be a cause of failure to prevent recurrences: reasons for change to active antiarrhythmic treatment at the time of the first detected episode. Europace 2008;10:21-7. doi:10.1093/europace/ eum 276

22 Naccarelli GV, Dell'Orfano JT, Wolbrette DL, Patel HM, Luck JC. Costeffective management of acute atrial fibrillation: role of rate control, spontaneous conversion, medical and direct current cardioversion, transesophageal echocardiography, and antiembolic therapy. Am / Cardiol 2000;85(10a):36D-45D. doi:10.1016/S00029149(00)00905-X

23 Gallagher MM, Guo XH, Poloniecki JD, Guan Yap Y, Ward D, Camm A). Initial energy setting, outcome and efficiency in direct current cardioversion of atrial fibrillation and flutter. J Am Coll Cardiol 2001;38:1498-504. doi:10.1016/S0735-1097(01)01540-6

24 Elhendy A, Gentile F, Khandheria BK, et al. Predictors of unsuccessful electrical cardioversion in atrial fibrillation. Am / Cardiol 2002;89:836. doi:10.1016/S0002-9149(01)02172-5

25 Hagens VE, Ranchor AV, Van Sonderen E, et al, RACE Study Group. Effect of rate or rhythm control on quality of life in persistent atrial fibrillation. Results from the Rate Control Versus Electrical
Cardioversion (RACE) Study. J Am Coll Cardiol 2004;43:241-7 doi:10.1016/j.jacc.2003.08.037

26 Singh BN, Singh SN, Reda DJ, et al, Sotalol Amiodarone Atrial Fibrillation Efficacy Trial (SAFE-T) Investigators. Amiodarone versus sotalol for atrial fibrillation. N Engl J Med 2005;352:1861-72. doi:10.1056/NEJMoa041705

27 Dankner R, Shahar A, Novikov I, Agmon U, Ziv A, Hod H. Treatment of stable atrial fibrillation in the emergency department: a population-based comparison of electrical direct-current versus pharmacological cardioversion or conservative management. Cardiology 2009;112:270-8. doi:10.1159/000151703

28 Gitt AK, Smolka W, Michailov G, Bernhardt A, Pittrow D, Lewalter T. Types and outcomes of cardioversion in patients admitted to hospital for atrial fibrillation: results of the German RHYTHM-AF Study. Clin Res Cardiol 2013;102:713-23. doi:10.1007/s00392-013-0586-x

29 Crijns HJ, Weijs B, Fairley AM, et al. Contemporary real life cardioversion of atrial fibrillation: Results from the multinational RHYTHM-AF study. Int J Cardiol 2014;172:588-94. doi:10.1016/j. ijcard.2014.01.099

30 Chevalier P, Durand-Dubief A, Burri H, Cucherat M, Kirkorian G, Touboul P. Amiodarone versus placebo and class Ic drugs for cardioversion of recent-onset atrial fibrillation: a meta-analysis. Am Coll Cardiol 2003:41:255-62 doi:10.1016/S0735 1097(02)02705-5

31 Camm AJ, Capucci A, Hohnloser SH, et al, AVRO Investigators. A randomized active-controlled study comparing the efficacy and safety of vernakalant to amiodarone in recent-onset atrial fibrillation. J Am Coll Cardiol 2011;57:313-21. doi:10.1016/j.jacc.2010.07.046

32 Packer DL, Mark DB, Robb RA, et al, CABANA Investigators. Effect of Catheter Ablation vs Antiarrhythmic Drug Therapy on Mortality, Stroke, Bleeding, and Cardiac Arrest Among Patients With Atrial Fibrillation: The CABANA Randomized Clinical Trial. IAMA 2019;321:1261-74. doi:10.1001/jama.2019.0693

Web appendix 1: GARFIELD-AF Registry Investigators Web appendix 2: Supplementary material 